at present quite satisfied with the success which I have had during twenty years' practice from perineal lithotomy and litholapaxy. I regard rectal distension as quite unnecessary, and not unattended with danger; in Case 1 the use of the rectal bag was followed by profuse hæmorrhage and subsequent muco-purulent discharge. Pending much stronger evidence than that which has hitherto been advanced in favour of the high operation, I shall continue to crush all stones capable of being crushed both in males and females, either in youth or adult life. I shall perform perineal lithotomy in cases not amenable to crushing, unless associated with some complication rendering it impossible to complete that operation, and I shall reserve suprapubic lithotomy for such cases, and for stones estimated to exceed three ounces in weight. These conclusions will, I believe, be generally shared by surgeons who have had large experiences in the various operations for the removal of vesical calculi. Manchester.

\section{RESULTS OF CICATRISING PROCESSES IN THE NEIGHBOURHOOD OF THE PORTAL FISSURE.}

BY HENRY F. A. GOODRIDGE, M.D., F.R.C.P., SEXIOR PHYSTCIAN TO THE ROYAL UNITHD HOSPTTAL, BaTH.

IT is well known that structures which derive their blood supply from vessels that pass through a cicatrix, or that traverse the area of a cicatrising process, are liable to undergo atrophy, and that this is due to the contractile property of the cicatricial tissue causing narrowing and diminution of calibre of the supplying vessels. The facts have been observed on the surface of the body, and, indeed, have been turned to good account in some instances in the practice of surgery. But it is not so generally recognised that similar secondary results may under certain circumstances follow cicatrisation occurring in internal parts, and prove serious drawbacks to the healing process. The events that take place here, and their relation to one another, are out of the sphere of direct observation, and the opportunity of tracing them by other methods is comparatively rare. Conceiving that the two cases about to be related afford such opportunity, I propose in this paper to invite attention to the subject, and to submit some pathological considerations in connexion therewith.

In the case of a small superficial ulcer of the stomach, the loss of mucous membrane at the spot with a trifling scar remaining is about the worst evil that can ensue. But it is far otherwise with a large, deep, and long-standing ulcer occupying the usual situation of the "chronic ulcer of the stomach." Besides stenosis of orifices, deformity of the organ is commonly noticed by writers as resulting from the cicatrisation of such an ulcer; it is rather with indirect, but not less important, results of the same that we are now concerned. It has happened to $m e$ in the course of $\mathrm{my}$ hospital practice to have a case of the latter class repeatedly under my care during a period of nine years extending from the first commencement of symptoms to the fatal termination, and then inspection of the anatomical condition was obtained. The following is a summary of the clinical history.

The patient, A. M- - was a lady's maid, aged thirty in January, 1866, when she was first admitted into hospital. She was moderately tall, of slender figure, and of pale complexion; she had two phthisical brothers, but said that her own health previously had been good. She had been suffering for three weeks from constant and severe vomiting after food, and from pain at the epigastrium, which was relieved, but not removed, by the vomiting; there was tenderness on pressure in the same locality. Her pulse was small and weak, her tongue pale and moist, her bowels sluggish, and her catamenia scanty. Under absolute rest, restricted diet, and nitrate of silver in half-grain doses, with a blister to the epigastrium, and an occasional enema, the symptoms speedily subsided; and with the substitution of iron and hydrocyanic acid, and a more liberal but still regulated diet, she made good progress, so that in the April following she was discharged "convalescent." In September, 1868, she was readmitted. She stated that shortly after she left the hospital she had a return of the symptoms, had to give up her situation in consequence, and had not been well since. The epigastric pain was very serere, and disturbed her sleep. Her catamenia had been absent for three months. She was put upon cimilar treatment. She romited only two or three times during her stay, the pain subsided, the catamenia reappeared, and she was discharged contalescent in the ensuing December. She now had some months of comparative, though not entire, freedom from complaint, and resumed domestic service. In the autumn of 1869 she caught cold at a catamenial period, whereupon thie function became completely suppressed. The epigastric pain returned, and she soon began to lose flesh and strength. She attended as an out-patient, but, no benefit accruing, she was admitted into the wards again in May, 1871 She was now in a much more pronounced state of anemis than heretofore. Epigastric pain, increased after food and disturbing her nights. was still her chief trouble, and there was the local tenderness on pressure as before, Omitting on this occasion the nitrate of silver, she had iron given her at once, and solution of sulphate of atropine was used hypodermically as an anodyne. She soon responded to this treatment, gained nearly a stone in weight in six weeks, and went out convalescent in July following. In Fobruary, 1872, she returned, stating that three weeks previously she had vomited blood to the amount of one pint. She was very anæmic, and there was marked exacerbation of the old symptoms. Her catamenia had now been absent for sixteen months. The sickness increasing, in spite of the treatment which succeeded on the preceding occasion, she was given nitrate of silver again in half-grain doses, and with good result. On resuming the iron, flying blisters were applied to the epigastrium and dressed with morphia ointment. Although bad fits of epigastric pain not unfrequently recurred, and she had now and then sickness, her appetite increased, she began to get up a little, she improved considerably in looks, and in April following was discharged relieved. Her history for the next two years and upwards was one of attendance off and on as an out-patient. She was admitted into hospital for the fifth time in September, 1874. Her condition at this date was urgent; her pallor and emaciation were both alike conspicuous. She had had a short time previously a recurrence of vomiting of blood; her pain in the epigastrium, increased after food as before, went right through to her back and interfered greatly with her sleep; she generally vomited after her meals, though at various intervals, and this brought a little ease. The existence of considerable dilatation of the stomach was now detected, and the vomited matters were found to contain sarcinæ. There was no response to treatment that formerly succeeded, nor to some other that was tried. Hypodermic morphia as an anodyne, with or without atropine combined, gave but very temporary relief. She was almost incessantly harassed with pain and sickness. On Oct. 16th she vomited dark grumous matter in which red blood dises were abundant. There were some little fluctuations in her condition afterwards, but on Oct. 30th she had similar hæmorrhagic vomit with melænic stools, and, this persisting, she gradually became exhausted, and died on Nov. 1st.

Necropsy, thirty-three hours after death--The stomach was found occupying the area traced out upon the abdominal parietes during life. It had several anhesions. First, it was inseparably adherent at the small curvature to the under surface of the right lobe of the liver by dense opaque neoplastic tissue, which occupied for the most part the small omentum. Another adbesion was to the pancreas and duodenum in its inferior transverse porion; and a third was to the left kidney, where also a very dense fibro-cartilage-like layer was present. There were slight adhesions to the spleen and to the diaphragm. The stomach at the same time exhibited a well-marked hour-glass contracticn. The effect of the latter, as appeared on laying open the interior, was to convert the pyloric segment into a separate sac, which was entered by a quasi-orifice of about the size of a crown-piece. A large irregular stellate cicatrix was discovered at the spot near the small curvature where externally was the dense adhesion to the liver; two or three small superficial ulcers were present near it. The mucous lining of this part was much puckered. At the fundus corresponding to the kidney adhesion was a large somewhat oval-shaped ulcer; it was between four and fire inches in length; its floor was constituted of the peritoneal coat, shreddy débris of muscular fibre, and some vessels traversing it. Its margin showed no trace of any reparative action, nor did that of any of the smaller ulcers present. There were several little deposits of melanic pigment in the vicinity 
of this ulcer, with some increased vascularity of the mucous surface, and sundry small ulcers and erosions. The pyloric segment, which, as before observed, formed a separate compartment, included the right half nearly of the great curvature, and was the healthiest portion of the organ, being quite free from ulceration. The pylorus was normal. The total capacity of the stomach was greatly augmented ; it was generally in a state of chronic catarrb, and it contained some of the melænic matter which was vomited during the last days of life, but no coagula. The duodenum was considerably dilated and contorted, the adhesion of the stomach to it just at its termination having apparently produced some constriction of the gut there; it also contained melænic matter. The liver had some slight adhesions of its convex surface; its texture was so friable that it broke under the smallest pressure-indeed the organ could not be handled without its giving way; the texture was also dry and granular. It weighed $32 \frac{1}{2} \mathrm{oz}$. There was little or no bile in the gallbladder. The spleen woighed 7 oz., and was pulpy. Except an old adhesion of the upper lobe of the left lung, there was nothing noteworthy elsewhere. On closer examination of the gastro-hepatic adhesion, it was found that the hepatic artery and some branches of the coronary artery lay very much in the focus of the dense neoplastic tissue, and the hepatic artery was distinctly observed to undergo an abrupt diminution in its calibre.

Proceeding now to remark on the pathological events in the foregoing case and to trace their connexion, the cicatrix found in the patient's stomach is obviously the first thing to claim attention. The characters of this cicatrix clearly denote that the pre-existing vlcer was a large one, and that in its extension in depth and progress outwards, having set up adhesive inflammation in the peritoneum, it came to have a thick floor of new tissue, if, indeed, it did not actually invade the contiguous portion of the liver. From the clinical record it is hardly less evident that the ulcer was one of long standing, and in the process of its healing underwent interruptions and relapses. The marked hour-glass deformity of the organ itself attests the magnitude of the lesiun and the abundance of contractile cicatricial tissue. Secondly, we observe that, although there were several small ulcers elsewhere in the stomach, and one pretty large one, there was no appearance of reparative action in any of them ; whence, I think, we may infer that these several ulcers were not in existence when the one above referred to cicatrised, but must have originated at a later period. Thirdly, we find that the hepatic artery and certain branches of the coronary were for a portion of their course involved in the dense neoplastic tissue which united the stomach and liver together in the site of the same cicatrix, which occupied, in fact, the small omentum. In seeking to understand how this came to pass, we must, I think, bear in mind that, besides the cicatricial fibroid tissue repairing the breach in the gastric wall, there were the products of the inflammatory process excited in the adjacent serous membrane, and rekindled with every relapse of ulceration; so that, with exuberant plastic material, the ultimate result, when at length reparation was consummated and the contractile property of the new tissue had come fully into play, would be a lumpy mass in which the normal relation of parts would be very much disturbed and the anatomical detail difficult to make out. The hepatic artery, however, was unmistakably identified, and it was found to be abruptly obstructed. Assuming that the liver is dependent upon this artery for its common nutrition, its condition corresponded; it was much under weight, and its texture was so friable, its cohesion so impaired, that it could not be hendled without giving way. But, in reference to the secondary ulcers observed on the mucous surface of the stomach, and which showed no reparative action, may we not conclude that they owed their origin, in part at least, to a similar constriction of the branches of the coronary artery causing impaired nutrition in the sphere of their distribution? Our next point would seem especially to favour this conclusion. Fourthly, the portion of the stomach included within the pyloric sac (as, for convenience sake, we may call it) was tound to be entirely free from ulceration; it was the healthiest portion of the organ. Now, this, we know, is just the portion that receives its blood supply, not from the coronary artery, but from the gastro-duodenalis, a branch of the hepatic artery, given off before this latter enters the small omentum, and therefore in the present instance before it was subjected to any constricting influence.

(To be concluded).

\section{THE OCCURRENCE OF MENORRHAGIA OR METRORRHAGIA DURING THE FEBRILE STATE.}

\author{
By ALFRED IIANTLE, M.D.
}

IN bringing before the notice of the profession the subject of menorrhagia or metrorrhagia as occurring during a febrile attack, I may at the outset say that my purpose in doing so is for the consideration of the treatment of such cases when the circumstances of some demand treatment. It is necessary to make this proviso, because most certainly the majority of cases of menorrhagia or metrorrhagia occurring during a febrile disease require no treatment; for the loss of blood may be considered to have a salutary effect upon the disease, and nature is probably doing what the practitioner of a generation ago considered the right course of treatment in all febrile diseases.

It is not an infrequent occurrence for zymotic diseases to be ushered in with hæmorrhage. This is frequently observed in the young when scarlatina or measles is making its appearance, at which time the hæmorrhage is most often seen to take place from the nasal mucous membrane. In older patients epistaxis or hæmatemesis is occasionally observed at the outset or early in the course of the fever; whilst in others-and this is particularly the case with measles, scarlatina, small-pox, typhus, typhoid, yellow, and intermittent fevers, and sometimes in pneumonia-the hæmorrhage shows itself from the mucous membrane of the uterus. In some cases this may mean nothing more than the normal process of menstruation taking place, which may or may not have been hastened a few days by the pyrexial attack, and the amount of blood lost may not necessarily be in excess; but in the strong and plethoric, and particularly in small-pox, typhus, typhoid, and yellow fever, the loss may sometimes be excessive and perilous, demanding active treatment. In other instances the hæmorrhage is quite unassociated with the normal menstrual act, when such cases may be said to be ordinary cases of uterine hæmorrhage or metrorrhagia induced by the febrile condition. I believe, however, that by far the largest number of cases of uterine hæmorrhage occurring during a febrile disease take place at or near the proper menstrual period, the circumstances being farourable to an excessive loss of blood. In considering what conditions are favourable to the development of menorrhagia or metrorrhagia during such an attack, we should remember that in the early stages of fever we have a quickened pulse with increased arterial tension. Incidentally, I may remark that in normal menstruation we have increased arterial pressure with slight pyrexia. In the uterus we have an organ with an unusually good blood supply, and, moreover, it is the only organ in the body from which blood escapes normally as a physiological process. With an increased vascular tension, it is only what we might then expect for blood to escape more freely from the mucous membrane, which probably feels and is most influenced by the increase of arterial pressure. A yet stronger factor, however, is probably at work in the causation of hæmorrhage in the febrile state, and it is the alterction in the character of the blood. What these alterations consist of we know as yet little or nothing; but whilst it has been said that in some fevers there is an increase in the fibrinforming constituents of the blood, undoubtedly in others there is a deficiency in these elements, and consequently a marked fluidity and want of coagulability is observed. I believe this to be the case in many of the zymotic fevers.

That the want of the properties of coagulation in uterine hæmorrhage is not explained by its being menstrual blood, and due possibly to the action of the acidity of the vaginal mucus, is proved by the fact that blood coming from the intestinal mucous membrane, or which has been abstracted by the operation of venesection, has the same characters. Trousseau, when speaking of intestinal bæmorrhage during enteric fevers, says," "At the necropsy of persons who have died of enteric fever, we often find bare mesenteric vessels at the bottom of the intestinal ulcerations. Hence it might be supposed that these hæmorrhages are attributable to the rupture of a mesenteric vessel during the process by which 